\title{
XV. New experimental researches on some of the leading doctrines of caloric; particularly on the relation between the elasticity, temperature, and latent heat of different vapours; and on thermometric admeasurement and capacity
}

\section{Andrew Ure M.D.}

To cite this article: Andrew Ure M.D. (1819) XV. New experimental researches on some of the leading doctrines of caloric; particularly on the relation between the elasticity, temperature, and latent heat of different vapours; and on thermometric admeasurement and capacity , Philosophical Magazine Series 1, 53:250, 87-102, DOI: 10.1080/14786441908652103

To link to this article: http://dx.doi.org/10.1080/14786441908652103

曲 Published online: 23 Jul 2009.

Submit your article to this journal

ЦIl Article views: 2

$Q^{\mathbf{Q}}$

View related articles \lceil 


\section{$\left[\begin{array}{ll}87 & ]\end{array}\right.$}

XV. New experimental Researches on some of the leading Doctrines of Caloric; particularly on the Relation letween the Elasticity, Temperature, and latent Heat of different Vapours; and on thermometric Admeasurement and Capacity. By Andrew URe, M.D.

[Continued from p. 44.]

TABLE I.

The elastic Force of the Vapour of Water in Inches of Mercury.

\begin{tabular}{|c|c|c|c|c|c|c|c|c|c|c|c|}
\hline 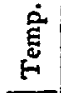 & 芯 & 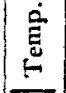 & 岕 & 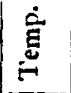 & 萢 & 总 & 苞 & 䆣 & 芯 & $\stackrel{s}{\tilde{g}}$ & 芯 \\
\hline $24^{\circ}$ & & $115^{\circ}$ & 820 & $195^{\circ}$ & 100 & $242^{\circ}$ & 53600 & 1270 & 86.300 & $295^{\circ}$ & \\
\hline 32 & & 120 & 0 & 200 & & & & $271 \cdot 2$ & & & \\
\hline 40 & 250 & 1125 & 88.30 & 205 & 25.900 & 245.8 & $57 \cdot 1$ & 273.7 & $91 \cdot 200$ & $297 \cdot 1$ & \\
\hline 50 & & 180 & $4: 36$ & 10 & & & & 75 & $93 \cdot 480$ & $|298 \cdot 8|$ & \\
\hline 55 & 0 & 195 & 5.070 & 2,2 & 30.000 & 250 & & $275 \cdot 7$. & 94.600 & 300 & \\
\hline 60 & & 140 & $5 \cdot 77$ & $16 \cdot 6$ & & $251 \cdot 6$ & & 277.9 & 97.800 & 3006 & \\
\hline 65 & $0^{\circ} 630$ & 145 & 6.600 & 220 & 35.540 & 254.5 & & $279 \cdot 5$ & 101. & 302 & \\
\hline 70 & & 150 & $7 \cdot 530$ & $21 \cdot 6$ & $36^{\circ}$ & 255 & 67 & 280 & $101 \cdot 900$ & 303.8 & \\
\hline 75 & 0.860 & 155 & 8.500 & 225 & $39 \cdot 110$ & $257 \cdot 5$ & & 281.8 & & 305 & \\
\hline 80 & 100 & 160 & 9.600 & $226 \cdot 3$ & 40.1 & 260 & $72 \cdot 300$ & 283.8 & & 306.8 & \\
\hline 85 & 1.17 & 165 & $10 \cdot 80$ & 230 & & $260^{\prime} 4$ & & 285.2 & & 308 & \\
\hline 90 & $1 \cdot 360$ & 170 & 2.05 & 230.5 & & $262-8 \mid$ & & $287 \cdot 2$ & & 310 & \\
\hline 95 & $1 \cdot 6$ & 175 & & 134.5 & & 264.9 & & 989: & & 311.4 & \\
\hline 00 & 1.860 & 180 & $5 \cdot 160$ & 235 & 47.5 & 265 & & 290 & 150 & 312 & \\
\hline & $2 \cdot 10$ & 185 & & $238 \cdot 5$ & $50^{\circ}$ & 267 & & $292 \cdot 3$ & & & \\
\hline & & 190 & 000 & 240 & & 269 & & 294 & & & \\
\hline
\end{tabular}

The apparatus employed in obtaining these results, has the peculiar advantage over all others, that the mercurial column is never heated. It is the concurrent opinion of all chemical philosophers, that caloric travels downwards in liquids with extreme slowness and difficulty. Indeed, Count Rumford's experiments led him to infer that heat could not descend in fluids at all.

It is evident that in my constructions, figures 1,2 , and 3 , only that small portion of quicksilver, within the vessels $A, B$, and $C$, will be affected by the heat, but the measuring column is beyond the reach of its influence.

A surprising accordance will be perceived between my numbers, and those given by $\mathrm{Mr}$. Dalton between $32^{\circ}$ and $212^{\circ}$, though mine were obtained with a different modification of apparatus. Above the boiling point, where the table of Mr. Dalton is deduced from calculation, the accordance soon ceases. But as my apparatus and mode of using it were precisely the same as in the former part of the range, my results, if entitled to confidence in the one case, must be so in the other. At $280^{\circ}$ Betancourt's number and mine are not much different, the former 
being 105 inches, the latter 102. Being perfectly convinced, by repeating the experiments in different circumstances, that $\mathrm{Mr}$. Dalton's ratio of progression, though apparently accommodated to the intervals between $32^{\circ}$ and $212^{\circ}$, could not serve for the higher ranges*, I endeavoured to discover a simple rule of more general application. It is above $212^{\circ}$, indeed, that for the purposes of art, the knowledge of the force of steam is required.

1 first tried the differential method, so useful for determining the distant links of a concatenated series.

Without doing much violence to the above numbers, the forces corresponding to $100^{\circ}, 110^{\circ}, 120^{\circ}, 130^{\circ}, 140^{\circ}$, and $150^{\circ}$, may be written in a series of which the 5 th order of differences $=0$. Then if $d^{\prime} d^{\prime \prime} d^{\prime \prime \prime} d^{i v} d^{r}$, represent the first terms, in the first, second, third, fourth, and fifth order of differences, the $n$th term of the series is

$$
\begin{aligned}
& a+\overline{n-1} \cdot d^{\prime},+\overline{n-1} \cdot \frac{n-2}{2} d^{\prime \prime},+\overline{n-1} \cdot \frac{n-2}{2} \cdot \frac{n-3}{3} \cdot d^{\prime \prime \prime}+ \\
& \overline{n-1} \cdot \frac{n-2}{2} \cdot \frac{n-3}{3} \cdot \frac{n-4}{4} \cdot d^{\prime \prime \prime \prime},+8 \mathrm{c} .
\end{aligned}
$$

In the above series for steam, $d^{\prime}=0 \cdot 6.5, d^{\prime \prime}=0 \cdot 19, d^{i \prime \prime}=$ $0.04, \mathrm{~d}^{\mathrm{iv}}=0.01, d^{\mathrm{v}}=0 . a=1.92$.

Example 1st. To determine the 8th term in the series, or the elastic force at $8 \times 10$, above $90^{\circ}$, (the first term $100^{\circ}$ being included) or at $170^{\circ}$.

Here $n=8$

$$
\begin{array}{ll}
a+\overline{n-1} \cdot d^{\prime}=1 \cdot 92+4 \cdot 55= & 6 \cdot 47 \\
\overline{n-1} \cdot \frac{n-2}{2} \cdot d^{\prime \prime}= & 4 \cdot 08 \\
\overline{n-1} \cdot \frac{n-2}{2} \cdot \frac{n-3}{3} \cdot d^{\prime \prime \prime}= & 1 \cdot 40 \\
\overline{n-1} \cdot \frac{n-2}{2} \cdot \frac{n-3}{3} \cdot \frac{n-4}{4} \cdot d^{\mathrm{iv}}= & \frac{0 \cdot 35}{12 \cdot 30}
\end{array}
$$

Observation gives 12.05 , forming a good accordance.

Example 2. Required the 10th term, or $n=10$. For $190^{\circ} \mathrm{F}$.

$$
\begin{array}{ll}
a+\frac{1-1}{n-1} \cdot d^{\prime}= & 7 \cdot 77 \\
\frac{n-1}{n-2} \cdot d^{\prime \prime}= & 6 \cdot 84 \\
n-1 \cdot \frac{n-2}{2} \cdot \frac{n-3}{3} \cdot d^{\prime \prime \prime}= & 3 \cdot 36 \\
n-1 \cdot \frac{n-2}{2} \cdot \frac{n-3}{3} \cdot \frac{n-4}{4} \cdot d^{\text {iv }}= & \frac{1 \cdot 26}{19 \cdot 23}
\end{array}
$$

At $190^{\circ}$ experiment makes it $19 \cdot 00$, still coinciding nearly.

* Dr. Young remarks on Dalton's ratio, "It is certain that this cannot be the law of nature, since about $394^{\circ}$ the elasticity would become uniform, and then decrease, if the ha be true."-Young's Natural Philosophy, 4to, vol. ii. p. 398. 
By the same equation we find the 20 th term or for $290^{\circ}$ to be $124 \cdot 28$; while experiment gives $120 \cdot 15$, showing a difference of 4.13 inches. At a higher point the error becomes greater. We here see that a geometrical series may coincide apparently through a considerable range with experiment, and yet be inaccurate when further extended.

Dissatisfied, therefore, with this approximation, I prosecuted the inquiry, and had the happiness to discover a very simple and beautiful ratio, which will actually apply through an extensive scale of temperature, and is incomparably easier in practice than the preceding rule. The elastic force at $212^{\circ}=30$ inches being divided by $1 \cdot 23$, will give the force for $10^{\circ}$ below; this quotient divided by 1.24 , will give that for $10^{\circ}$ lower; and so on progressively. To obtain the forces above $212^{\circ}$, we have merely to multipty $30^{\circ}$ by the ratio 1.23 , for the force at $222^{\circ}$; this product by $1 \cdot 22$ for that at $232^{\circ}$, and thus for each successive interval of $10^{\circ}$ above the boiling point.

Thus $30 \times 1 \cdot 23=\mathrm{F}_{222^{\circ}} . \quad 30 \times 123 \times 1.22=\mathrm{F}_{232^{\circ}}$, using $\mathrm{F}$ to denote the force at any temperature $n$, according to the notation of Laplace.

By departing from the point of $210^{\circ} \mathrm{F}$, we shal: obtain results equally accurate, but more convenient for comparison with the experimental table. The following numbers exhibit the correspondence of this ratio with actual observation.

TABLE II.

Observed Elasticity of aqueous Vapour compared with the Ratios.

\begin{tabular}{|c|c|c|c|c|c|c|c|c|}
\hline 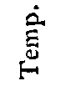 & $\begin{array}{l}\text { Calcul. } \\
\text { Force. }\end{array}$ & Exper. & 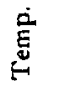 & $\begin{array}{l}\text { Calcul. } \\
\text { Force. }\end{array}$ & 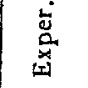 & DALTON & BETANC & ROBISON. \\
\hline $210^{\circ}$ & $28 \cdot 9$ & $28 \cdot 9$ & $210^{\circ}$ & 289 & $28 \cdot 9$ & 2884 & 288 & $28 \cdot 65$ \\
\hline 200 & $23 \cdot 5$ & $23 \cdot 6$ & 220 & $35 \cdot 54$ & $35 \cdot 54$ & 34.99 & & $35 \cdot 80$ \\
\hline 190 & 190 & 190 & 230 & $43 \cdot 36$ & 4310 & $4 ! \cdot 75$ & $45 \cdot 5$ & 4470 \\
\hline 180 & $15 \cdot 2$ & $15 \cdot 16$ & 240 & $52 \cdot 46$ & 51.70 & 4967 & & 5490 \\
\hline 170 & 1207 & 120.5 & 250 & 6295 & $61 \cdot 90$ & 5821 & & 6680 \\
\hline 160 & $9 \cdot 50$ & 960 & 260 & 7491 & $72 \cdot 30$ & 67.73 & $80 \cdot 17$ & 80.30 \\
\hline 150 & $7 \cdot 42$ & 758 & 270 & 88.39 & $86 \cdot 30$ & 7783 & & $94 \cdot 10$ \\
\hline 140 & 5.75 & $5 \cdot 77$ & 280 & 103.41 & $101 \cdot 90$ & $88 \cdot 7.5$ & 105.12 & 10.590 \\
\hline 130 & 442 & 436 & 290 & 11995 & $120 \cdot 15$ & $100 \cdot 12$ & & \\
\hline 120 & $3 \cdot 37$ & $3 \cdot 33$ & 300 & $137 \cdot 94$ & $139 \cdot 70$ & $111 \cdot 81$ & & \\
\hline 110 & $2 \cdot 55$ & $2 \cdot 45$ & 310 & $157 \cdot 25$ & 16130 & 123.53 & & \\
\hline 100 & 192 & 186 & 320 & 177.70 & & 13500 & & \\
\hline 90 & 1.43 & $1 \cdot 36$ & & & & & & \\
\hline 80 & 1.06 & 1.01 & & & & Temp. & BETANC. & RoBISON \\
\hline 70 & 0.77 & 0.726 & & & & & & \\
\hline 60 & 0.56 & 0516 & & & & $32^{\circ}$ & 0.0 & $\begin{array}{l}0.0 \\
0.12\end{array}$ \\
\hline 50 & 0.40 & $\begin{array}{l}0.36 \\
0.95\end{array}$ & & & & $\begin{array}{l}50 \\
80\end{array}$ & & 0.12 \\
\hline 40 & 028 & 0.25 & & & & 80 & 0.81 & $\begin{array}{l}082 \\
160\end{array}$ \\
\hline 30 & 0.20 & 0.19 & & & & 100 & 1.65 & 160 \\
\hline 20 & 014 & 0.14 & & & & 120 & 29.5 & 300 \\
\hline 10 & 0.098 & & & & & 140 & 500 & $5 \cdot 15$ \\
\hline 0 & 0.068 & & & & & 160 & 900 & 865 \\
\hline & & & & & & 180 & $14 \cdot(10$ & $14 \cdot 05$ \\
\hline & & & & & & 200 & $22 \cdot 50$ & 2262 \\
\hline
\end{tabular}


The rule on which the preceding table is formed, may be expressed in a manner better fitted to give directly the elastic force corresponding to any given temperature mederately distant from $212^{\circ}$. It becomes also more accurate.

Let $r=$ the mean ratio between $210^{\circ}$ and the given temperature; $n=$ the number of terms (each of $10^{\circ}$ ) distant from $210^{\circ}$; $F=$ the elastic force of steam in inches of mercury.

Then, Log. of $\mathrm{F}=\log .28 \cdot 9 \pm n . \log . r$; the positive sign being used above, the negative below $210^{\circ}$.

Or by common arithmetic, multiply or divide 28.9 , according as the temperature is above or below $210^{\circ}$, by the mean ratio, involved to a power denoted by the number of terms. The product or quotient is the tension required.

Example 1st. The temperature is $140^{\circ}$. What is the corresponding elasticity of the vapour from water heated to that point?

$140^{\circ}$ is 7 terms of $10^{\circ}$ each under $210^{\circ} ; 1.26$ is the mean ratio $=\frac{1 \cdot 23+1 \cdot 29}{2} ;$ and, consequently, $r=1 \cdot 26 ; n=7$.

$$
\text { Log. } 28 \cdot 9=1 \cdot 46090
$$

Log. $1 \cdot 26 \times 7=0 \cdot 10037 \times 7=-0 \cdot 70259$

the logarithm of $\quad . \quad \ldots \quad \ldots \quad 5 \cdot 732$ inches.

$$
0.75831 \text {, which is }
$$

Experiment gives .. $\quad . . \quad \ldots \quad 5 \cdot 77$, difference 04 , inconsiderable.

Example 2. What is the tension of steam at the temperature of $290^{\circ}$ ?

$$
\begin{aligned}
& r=\frac{1 \cdot 23+1 \cdot 16}{2}=1 \cdot 195 \quad n=8 \\
& \log .28 .9=1 \cdot 46090
\end{aligned}
$$

8 Log. $r=8 \times 0.07737=+0.61896$

Log. of $120 \cdot 02$ inches 207986

At $290^{\circ}$ by experiment $=120 \cdot 15$.

Example 3. Temperature $250^{\circ}$. Force of steam in contact with water?

$$
\begin{aligned}
& r=\frac{1 \cdot 23+1 \cdot 20}{z}=1 \cdot 21.5 \quad n=4 \\
& \text { Log. } 28 \cdot 9=1 \cdot 46090 \\
& 4 \text { Log. } r=4 \times 0.08458=+\frac{0.33832}{\text { Log. of } 62.98}
\end{aligned}
$$

\section{At $250^{\circ}$ Experiment $61 \cdot 90$}

At these high heats, it is very possible that the experiment may be in error by one inch, which is the whole difference here. About half a degree of Fahrenheit misnoted, would give this deviation.

Such a correspondence, therefore, of observation with the cal- 
culated results, shows that we have found a rule of perfect accuracy for all purposes of engineering, \&c. If I am asked whether this formula coincides at everv. link with the chain of nature, I freely acknowledge, that I do not imagine it strictly so to do. But still it affords approximations such, that within moderate limits, I cannot tell whether to place more confidence in them, or in those found by experiment. It has moreover the rare advantage of being extremely simple, and level to the capacity of all practical men.

In Biot's excellent work above quoted, where many of the hitherto vague disquisitions of physical science have been happily brought within the pale of genmetry, this celebrated philosopher has deduced, from Mr. Dalton's experiments on the force of steam, a general formula for determining its elasticity at any temperature.

In investigating this formula, he represents the decrease of the logarithms of the elastic forces by a series of terms of the form $a n+b n^{2}+c n^{3} ; a b c$ being constant coefficients.

$$
\text { Thus, Log. } \mathrm{F}_{n}=\log .30+a n+b n^{2}+c n^{3} \text {. }
$$

It is unnecessary to employ powers of $n$ higher than the cube, because their coefficients would be insensible, as the calculation will show. To determine the coefficients $a \hat{b} c$, he makes use of the elastic forces, observed at the temperatures on the centigrade scale of $100^{\circ}, 75^{\circ}, 50^{\circ}$, and $25^{\circ}$; whence result these conditions,

$$
\begin{array}{ll}
n=0 & \mathrm{~F}=30.00 \text { inches } \\
n=25 & \mathrm{~F}_{25}=11.25 \\
n=50 & \mathrm{~F}_{50}=3.50 \\
n=75 & \mathrm{~F}_{75}=0.910
\end{array}
$$

Substituting these conditions in the above general formula, and bearing in mind that the logarithm of a fraction is. equal to the logarithm of the numerator minus the logarithm of the denominator, we have the three following equations of conditions.

$$
\begin{aligned}
& -04259687=25 . a+625 b+15625 c . \\
& -0.9330519=50 . a+2500 b+125000 c . \\
& -1.5150799=75 . a+5625 b+421875 c .
\end{aligned}
$$

Doubling the first, and subtracting it from the second, $a$ disappears ; trebling it, and suhtracting it from the third, $a$ also disappears. Then dividing each of the resulting equations by the coefficient of $l$, we have

$$
\begin{aligned}
& -0.00006489160=b+75 c . \\
& -0.00006404635=b+100 c .
\end{aligned}
$$

Subtracting the one of these from the other, $b$ will disappear; and dividing it by the coefficient of $c$, we shall have $c$. Next, 
by substituting the value of $c$ in one of these equations, we get $l$. Lastly, putting $b$ and $c$ in one of the two first equations, we have a. Thus we find

$$
\begin{aligned}
& a=-0.01537419550 \\
& b=-0.00006742735 \\
& c=+0.00000003381
\end{aligned}
$$

Whence the whole formula Log. $\mathrm{F}_{n}=\log .30+a n+b n^{2}+c n^{3}$ is completely determined, and may serve for calculating $\mathrm{F}_{n}$, relative to any proposed value of $n$.

If we make, for example, $n=100$, we shall have the elastic force at 100 degrees below the boiling point, or at the temperature of melting ice. We thus obtain

$$
\text { Log. } F_{n}=1 \cdot 4771213-2 \cdot 1778831=-0 \cdot 7007618 \text {. }
$$

Or employing negative indices in order to make use of the ordinary logarithmic tables,

$$
\begin{aligned}
\log . F_{n} & =\bar{l} \cdot 2992382, \text { whence } \\
F_{n} & =0 \cdot 19917 \text { inches; and observation } \\
\text { gives us } 0 \cdot 200 . &
\end{aligned}
$$

The error is obviously insensible; and we may adopt, says $\mathrm{M}$. Biot, our formula as representing the experiments of $\mathrm{Mr}$. Dalton. To introduce the Fahrenheit degrees into the formula, calling them $f$, and counting from $212^{\circ}$, we have $\frac{3}{9} f=n$; and substituting this value of $n$ in the preceding formula, we obtain

$$
\begin{aligned}
& a=-0.00854121972 \\
& b=-0.00002081091 \\
& c=+0.00000000580,
\end{aligned}
$$

whence Log. $\mathrm{F}_{f}=1 \cdot 4771213+a f^{3}+b f^{2}+c f^{3}, f$ being the number of degrees of Fahrenheit, reckoning them from $212^{\circ}$, positive below and negative above this point of departure.

By the above formula, thus elaborately investigated by M. Biot, I have computed the elastic forces of steam at the three successive temperatures of $232^{\circ}, 262^{\circ}$, and $312^{\circ}$, or $20^{\circ}, 50^{\circ}$ and $100^{\circ}$, above the boiling point of Fabrenheit's scale.

In the first case we have $f=-20$ and $a f^{\prime}+b f^{2}+c f^{3}=20$ $+400 b-8000 c ; f$ is negative, being above the point of departure $212^{\circ}$, and, consequently, the products af and $c f^{3}$ are positive, while $b f^{2}$ becomes negative.

$$
\begin{aligned}
& 20 a=0 \cdot 170824 \\
& 400 b=-0.008324 \\
& 8000 c=+0 \cdot 000046 \\
& 0 \cdot 162546+\log .30 \text { or } 1 \cdot 477121 \\
& 1 \cdot 477121 \\
& \text { Log. of } 43 \cdot 62=1 \cdot 639667
\end{aligned}
$$


on some of the leading Doctrines of Caloric, Eंc.

By Biot's formula therefore at $232^{\circ} \mathrm{F}$. .. $43 \cdot 620$

$\begin{array}{lllllll}\text { My experiments } & \ldots & \ldots & \ldots & \ldots & \ldots & 44 \cdot 700\end{array}$

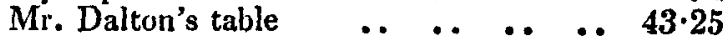

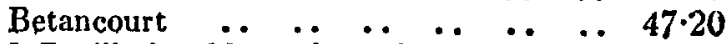

By M. Pouillet's table at the end of Biot's lst vol. computed from the above formula .. 43.500

The difference between Biot and my experiments.here is only $1 \cdot 10$ inches.

$2 d$ Example. Temperature $262^{\circ}$ Fahr. $f=50$

$50 a=0.4270609$

$2500 b=-0.0520272$

$125000 c=+0.0007250$

$$
\begin{aligned}
& 0.3757587 \\
& \text { Log. } 30=1.4771213
\end{aligned}
$$

The disparity between Biot's formula and experiment becomes more apparent now: it amounts to 3.335 inches.

At $266^{\circ}$ Fahr. which corresponds to $130^{\circ}$ centigrade, I make it from Biot's frst formula 77.053 , while at $130^{\circ}$ by M. Pouillet, it is $75.68 *$; difference 1.973 . Finally,

At the temperature of $312^{\circ}, f=100^{\circ}$

$$
\begin{aligned}
& 100 a=0.854121972 \\
& 10 \cdot 000 b=-0.208109100 \\
& 1000000 c=+0.005800000 \\
& 0.651812872 \\
& 1 \cdot 477121300 \\
& \text { Log. of } \mathrm{F}_{f}=2 \cdot 128934172 \mathrm{~F}_{f}=\mathrm{F}_{100}=134.57 \\
& \text { Experiment gives } \quad \mathrm{I} 67.00 \\
& \text { Mr. Dalton's table } 125 \cdot 85
\end{aligned}
$$

The difference between experiment, and both calculations, is now excessive, and even between the two latter it amounts to nearly nine inches.

From this ample investigation, we may legitimately conclude,

* $130^{\circ}$ centigr. gives by M.P. force of vapour $=1907.07$ millimetres; of which taking 25.4 to the English inch, we hare $\frac{1907 \cdot 07}{25 \cdot 4}=75.08$ as above. 
that we ought to receive such geometrical representations witn great caution. M. Biot, indeed, with a candour becoming his genius, admits these formulæ to be merely tentative approximations. The high reputation of this philosopher, and the geometrical skill here displayed, might have led the scientific world to repose confidence in his formula, within the limits of $55 \frac{\mathrm{I}}{2} \mathrm{de}-$ grees centigrade $=100 \mathrm{Fahr}$. It was therefore entitled to a deliberate examination.

It is curious to observe that my very simple formula, Log. $F=\log .28 \cdot 9 \pm n \cdot \log . r$, gives good approximations, through a much more extensive range, than the elaborate formula of the distinguished French geometer. Even when carried so high as the 3 ioth degree of Fahr., we have

$$
\begin{aligned}
& \text { Log. } 28 \cdot 9+n . \log . r=2 \cdot 19810=\mathrm{L}, \mathrm{F}_{100} \text {; hence } \\
& F_{100}=157 \cdot 8 \text {. }
\end{aligned}
$$

Experiment gives $161 \cdot 3$, a difference of only $3 \frac{1}{2}$ inches at this prodigious elasticity; which may be deemed altogether unimportant in practice.

Biot's formula gives a result 31 inches, and Mr. Dalton's 40 in defect.

Of Professor Robison's higher numbers, it is merely necessary to examine the successive differences for every $10^{\circ}$ above $212^{\circ}$. 'These are $7 \cdot 2,8 \cdot 9,10 \cdot 2,11 \cdot 9,-13 \cdot 5,13 \cdot 8,11 \cdot 8$, and the second differences are $+1 \cdot 7+1 \cdot 3+1 \cdot 7+1 \cdot 6+0 \cdot 3-2 \cdot 0$.

Such striking irregularities cannot exist in the progression of nature. Betancourt's are liable to a similar censure. We may fund indeed small discrepancies in the best observations at such temperatures.

$\S$ II. Experiments to determine the elastic Forces of the $V a-$ pours of Alcohol, Ether, Oil of Turpentine, and Petroleum or Naphtha.

The determination of the elasticities of these vapours is a very interesting problem in chemical philosophy. It may possibly unfold the law which connects temperature and elastic energy, and it may furnish likewise some useful applications.

Mr. Dalton has examined the subject with considerable care.

My experiments were performed with the apparatus above described, and were verified by frequent repetitions. The following results were noted down during the progress of the experiments. 


\section{TABLE III.}

\section{Elastic Forces of the Vapours of Alcokol, Ether, Oil of Tur-} pentine, and Petroleum or Naphtha.'

\begin{tabular}{|c|c|c|c|c|c|c|c|}
\hline \multicolumn{2}{|c|}{ Ether. } & \multicolumn{2}{|c|}{$\begin{array}{c}\text { Alcohol sp.gr. } \\
0.819 .\end{array}$} & \multicolumn{2}{|c|}{$\begin{array}{c}\text { Alcohol sp.gr. } \\
0813 .\end{array}$} & \multicolumn{2}{|c|}{ Petroleum. } \\
\hline$\underset{⿱ ㇒}{\stackrel{\dot{E}}{E}}$ & $\begin{array}{l}\text { Force of } \\
\text { Vapour. }\end{array}$ & 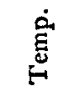 & $\begin{array}{l}\text { Force of } \\
\text { Vapour. }\end{array}$ & 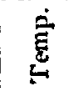 & $\begin{array}{l}\text { Force of } \\
\text { Vapour }\end{array}$ & 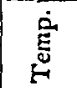 & $\begin{array}{l}\text { Force of } \\
\text { Vapour. }\end{array}$ \\
\hline $34^{\circ}$ & 620 & 32 & 0.40 & $193^{\circ} .5$ & $46 \cdot 60$ & $316^{\circ}$ & $30 \cdot 00$ \\
\hline 44 & $8 \cdot 10$ & 40 & 0.56 & $196 \cdot 3$ & $50 \cdot 10$ & 320 & $31 \cdot 70$ \\
\hline 54 & $10 \cdot 30$ & 45 & 0.70 & 200 & $53 \cdot 00$ & 325 & $34 \cdot 00$ \\
\hline 64 & $13 \cdot 00$ & 50 & 0.86 & 206 & $60 \cdot 10$ & 330 & $36 \cdot 40$ \\
\hline 74 & $16 \cdot 10$ & 55 & $1 \cdot 00$ & 210 & 65.00 & 335 & 38.90 \\
\hline 84 & $20 \cdot 00$ & 60 & 1.23 & 214 & 6930 & 340 & $41 \cdot 60$ \\
\hline 94 & $24 \cdot 70$ & 65 & 1.49 & 216 & $72 \cdot 20$ & 345 & $44 \cdot 10$ \\
\hline \multirow[t]{2}{*}{104} & $30 \cdot 00$ & 70 & 1.76 & 220 & $78 \cdot 50$ & 350 & $46 \cdot 86$ \\
\hline & & 75 & $2 \cdot 10$ & 225 & $87 \cdot 50$ & 355 & $50 \cdot 20$ \\
\hline \multirow[t]{2}{*}{ 2nd. } & Ether. & 80 & $2-45$ & 230 & $94 \cdot 10$ & 360 & $53 \cdot 30$ \\
\hline & & 8.5 & 2.93 & 232 & $97 \cdot 10$ & 365 & 56.90 \\
\hline $105^{\circ}$ & $30 \cdot 00$ & 90 & $3 \cdot 40$ & 236 & $103 \cdot 60$ & 370 & $60 \cdot 70$ \\
\hline 110 & $32 \cdot 54$ & 95 & 3.90 & 238 & $106 \cdot 90$ & 372 & $61 \cdot 90$ \\
\hline 115 & 85.90 & 100 & 4.50 & 240 & 111.24 & 375 & 64.00 \\
\hline 120 & $39 \cdot 47$ & 105 & $5 \cdot 20$ & 244 & 118.20 & \multirow{2}{*}{\multicolumn{2}{|c|}{ Oil of Turpen. }} \\
\hline \multirow{2}{*}{$\begin{array}{l}125 \\
130\end{array}$} & $43 \cdot 24$ & 110 & 6.00 & 247 & $122 \cdot 10$ & & \\
\hline & $47 \cdot 14$ & 115 & $7 \cdot 10$ & 248 & $126 \cdot 10$ & \multirow{4}{*}{$\underset{\dot{\Xi}}{\dot{\Xi}}$} & \multirow{4}{*}{$\begin{array}{l}\text { Force of } \\
\text { Vapour. }\end{array}$} \\
\hline 135 & 51.90 & 120 & $8 \cdot 10$ & 2497 & 151.40 & & \\
\hline 140 & $56 \cdot 90$ & 125 & $9 \cdot 25$ & $25 !$ & $132 \cdot 30$ & & \\
\hline$\$ 45$ & $62 \cdot 10$ & 130 & $10 \cdot 60$ & 252 & $138 \cdot 60$ & & \\
\hline 150 & $67 \cdot 60$ & 135 & $12 \cdot 15$ & 2543 & 1438.70 & $304^{n}$ & 30.00 \\
\hline 155 & $73 \cdot 60$ & 140 & 13.90 & $258 \cdot 6$ & $151 \cdot 60$ & $307 \cdot 6$ & \\
\hline 160 & $80 \cdot 30$ & 145 & $15 \cdot 95$ & 260 & $155 \cdot 20$ & 310 & 38.00 \\
\hline 165 & $86 \cdot 40$ & 150 & $18 \cdot 00$ & 262 & $161 \cdot 40$ & $\begin{array}{l}310 \\
315\end{array}$ & $\begin{array}{l}33.50 \\
55.20\end{array}$ \\
\hline 170 & $92 \cdot 80$ & 155 & $20 \cdot 3^{\prime \prime}$ & 264 & 166.10 & $\begin{array}{l}3150 \\
320\end{array}$ & $\begin{array}{l}35.20 \\
37.06\end{array}$ \\
\hline 175 & $99 \cdot 10$ & 160 & 22.601 & & & $\begin{array}{l}320 \\
300\end{array}$ & 37.80 \\
\hline 180 & $108 \cdot 30$ & 165 & $25 \cdot 40$ & & & 306 & 40.00 \\
\hline 185 & $116 \cdot 10$ & 170 & $28 \cdot 30$ & & & 326 & $\begin{array}{l}40 \cdot 20 \\
40 \cdot 30\end{array}$ \\
\hline 190 & 12480 & 173 & $30 \cdot 00$ & & & 830 & \\
\hline 195 & 133.70 & 178.3 & 53.50 & & & 336 & 4500 \\
\hline 200 & 142.80 & 180 & 34.75 & & & 340 & $47 \cdot 30$ \\
\hline 205 & 151.30 & $182 \cdot 3$ & $36 \cdot 40$ & & & 343 & 4940 \\
\hline 210 & 166.00 & 185.3 & 39.90 & & & 347 & $51 \cdot 70$ \\
\hline & & 190 & $43 \cdot 20$ & & & 350 & $53 \cdot 80$ \\
\hline & & & & & & 354 & \\
\hline & & & & & & 351 & \\
\hline & & & & & & 362 & $62 \cdot 40$ \\
\hline
\end{tabular}

Remarks on the preceding Table.

The ether of the shops as prepared by the eminent London apothecaries boils generally at $112^{\circ}$; but when washed with water, or redistilled, it boils at $104^{\circ}$ or $105^{\circ}$. It may by rectification, however, he made to boil at a still lower temperature.

Concerning the boiling point of oil of turpentine, curious (may we say ridiculous) discrepancies exist in our systems of chemistry. Dr. Murray, for example, in the table of the scale of temperature 
at the end of the first volume of his valuable System, last edition, places the boiling point of oil of turpentine at $560^{\circ}$. Mr. Dalton, vol. i. p. 39, of his new System of Chemical Philosophy, says : "Several authors have it that oil of turpentine boils at $560^{\circ}$. I do not know how the mistake originated, but it boils below $212^{\circ}$, like the rest of the essential oils." I made with much care several experiments on this point, previous to ascertaining the force of its vapour, and found its boiling point to be about $316^{\circ}$. When recently distilled, however, it will boil at $305^{\circ}$. Did it boil below, or even at $212^{\circ}$, as Mr. Dalton asserts, then, long before the included portion in the above experiments had reached the 304 th degree, it would have acquired such an elasticity as to support a high column of mercury, instead of being barely in equilibrio with the atmospheric pressure.

Plunge a phial half filled with fresh oil of turpentine into a metal cup containing any fixed oil. Heat the cup gradually. It will be found that, at the temperature of $316^{\circ}$, the oil remains in steady ebullition, as indicated by a thermometer suspended in the centre of the phial. Prior to this, even at $212^{\circ}$, some small bubbles will be evolved, principally owing to the moisture dispersed in the pores of the oil, from the water originally mixed with the crude turpentine in its distillation. If the heat be very rapidly thrown in, while the upper surface of the oil of turpentine has the area only of a one or two ounce phial, it is possible to heat it to $360^{\circ}$ or $370^{\circ}$, in apparent contradiction to the theory of latent heat; for when a liquid boils in an open vessel, according to Dr. Black, its temperature should remain stationary. The true cause of this phænomenon is developed towards the conclusion of this memoir. The specific caloric of the vapour of the volatile oil is so small, compared to that of water, that the heat may readily be quicker introduced than the boiling process can abstract it. Concerning the boiling point of this oil, I have since inquired of a manufacturer; and he states its boiling point at $320^{\circ}$. Essential oil of rosemary, when kept for some time, boils at $270^{\circ}$; recent oil at $212^{\circ}$. To assign the cause of this difference, is foreign to our present object.

The vapour of ether follows nearly the same rate of expansion as water, if we start from their respective boiling points. This was observed also in Mr. Dalton's experiments; and from this single analogy, chiefly, he laid down the general law, "that the variation in the force of vapour from all liquids is the same for the same variation of temperature, reckoning from vapour of any given force."

My experiments on oil of turpentine and petroleum show the fallacy of this generalization, if we reckon the common thermometric scale a tolerably correct index of temperature; but if, 
with $\mathrm{Mr}$. Daiton, we consider our thermometric scale, as very etroneous, then either itself is an exception to its own law, to use this paradoxical, though just expression. In consequence of his peculiar thermometric ideas, Mr. Dalton has abrogated the above law, which he had himself framed; though it is curious to observe, in some respectable treatises on chemistry, both hypotheses detailed, without indicating their mutual incompatibility. M. Biot, likewise, far from imagining that the law had been repealed for eight or nine years, proposes to jurlge by its provisions of the total elastic force of every vapour at $100^{\circ}$ centigrade, to serve as the basis of the determination of their respective specific gravities at that temperature *

My experiments show that from $105^{\circ}$ to $167^{\circ} .5$ Fahrenheit, ether trebles the tension of its vapour, as water also does from $212^{\circ}$ to $272^{\circ} \cdot 7$; both containing nearly, but by no means exactly, equal intervals of the Fahrenheit graduation. According to $\overline{\mathrm{Mr}}$. Dalton's corrected scale of temperature, we have

$212^{\circ}$ Fah. $=212^{\circ}$ Dalton. $105^{\circ}$ Fah. $=119^{\circ}$ Dalton.

$273 \mathrm{~F} .=256.4 \mathrm{D} . \quad 167 \cdot 5 \mathrm{~F} .=176 \mathrm{D}$.

real interval $=44.4$ by Dalton. By Dalton $57=$ the real interval of temperature.

Thus we see, that while the interval for trebling the tension of ethereal vapour is $57^{\circ}$, that for aqueous vapour is only $44^{\circ} \cdot 4$; quantities that are to each other nearly as 100:80. Hence, according to this eminent chemist, ether must take for trebling the force of its vapour a fifth part more heat than water does.

I hope presently to be able to adduce satisfactory experimental evidence, that our thermometric indications are not at all so unequable as Mr. Dalton conceives.

Meanwhile, in examining closely the table of the vapour of ether, a beautiful analogy with that of water presented itself. The series of ratios representing the progression of the latter being lowered a single step, will accurately fit the former. At 30 inches of elasticity 1.23 was our initial number for aqueous vapour; for ethereal, it becomes $1 \cdot 22$; increasing or diminishing by unity each time in the second decimal figure, according as we descend or ascend by intervals of $10^{\circ}$ of the Fahrenheit scale.

The following is a general view of the results.

* " On peut calculer par ln loi de M. Dalton, quelle loit être, pour chacun d'eux, la force élastique totale de sa vapeur à la température de 100 degrés."-Traité de Physique, tome i. p. 393. 
TABLE IV.

The olserved Tension of ethereal Vapour compared with the Ratios 1·22, 1·23, \&c. and 1-22, 1·21, E'c.

\begin{tabular}{|c|c|c||c|c|c|}
\hline Temp. & Quotients. & Expert. & Temp. & Product. & Expert. \\
\hline $104^{\circ}$ & - & $30 \cdot 00$ & $105^{\circ}$ & - & $30 \cdot 0$ \\
94 & $24 \cdot 7$ & $24 \cdot 70$ & 115 & $36 \cdot 6$ & $35 \cdot 9$ \\
84 & $20 \cdot 2$ & $20 \cdot 00$ & 125 & $44 \cdot 3$ & $43 \cdot 24$ \\
74 & $16 \cdot 3$ & $16 \cdot 10$ & 135 & $53 \cdot 4$ & $51 \cdot 9$ \\
64 & $13 \cdot 06$ & $13 \cdot 00$ & 145 & $63 \cdot 6$ & $62 \cdot 1$ \\
54 & $10 \cdot 3$ & $10 \cdot 3$ & 155 & $75 \cdot 4$ & $73 \cdot 6$ \\
44 & $8 \cdot 1$ & $8 \cdot 1$ & 165 & $88 \cdot 2$ & $86 \cdot 4$ \\
34 & 6.35 & $6 \cdot 2$ & 175 & $102 \cdot 0$ & $99 \cdot 1$ \\
& & & 185 & $117 \cdot 3$ & $116 \cdot 1$ \\
& & & 195 & $134 \cdot 0$ & $133 \cdot 7$ \\
& & & 205 & $151 \cdot 3$ & $151 \cdot 3$ \\
\hline
\end{tabular}

The numbers derived from calculation give a surprising accordance with those observed in the lower range. In the upper range, the correspondence is as good as the delicacy of the experiments at such temperatures could permit us to expect. The experiments have been presented without modification. I must own, that when first the above perfect coincidence appeared, it gave me no small pleasure, as it led me to suppose that I had discovered the hidden chain of nature.

In treating of the vapour of alcohol, Mr. Dalton considers it as irregular in the progress of its elastic force by heat, owing to its not being a homogeneous liquid. He suspects "that the elastic force in this case is a mixture of aqueous and alcoholic vapour." I cannot see the cogency of this argument; for, if the separate bodies have a regular progression, the mixture ought not surely to be anomalous. I believe, however, that if the experiments were made with due accuracy, alcohol would be found as methodical in the elastic march of its vapour as other bodies. The following table will afford satisfactory proofs of the justness of these views. For absolute alcohol, the progression is probably as simple as that of the preceding vapours. But for alcohol, sp. gr. 0.813, which though highly rectified contains not a little water, we should expect it to result from a composition or modification of ratios. After some search on this principle, I accordingly found it. Starting from the boiling point $174^{\circ}$, or, for the convenience of comparison with the table, from the decade $170^{\circ}$, we move not by a unit, as before, but by a unit and a tenth ; or the initial ratio 1.26 is affected at each step or term 
of $10^{\circ}$, with the number \pm 0.011 , the signs being employed as in the preceding cases.

\section{TABLE $V$.}

Elastic Force of the Vapour of Alcohol compared with the Ratins.

\begin{tabular}{|c|c|c|c|c|c|c|c|c|}
\hline Temp. & $\begin{array}{c}\text { Calcu. } \\
\text { lat. }\end{array}$ & $\begin{array}{c}\text { Ob- } \\
\text { served }\end{array}$ & Temp. & $\begin{array}{l}\text { Calcu- } \\
\text { lat. }\end{array}$ & $\begin{array}{c}\text { Ob- } \\
\text { served. }\end{array}$ & Temp. & $\begin{array}{l}\text { Calcu- } \\
\text { lat. }\end{array}$ & $\begin{array}{l}\text { Ob- } \\
\text { served. }\end{array}$ \\
\hline $250^{\circ}$ & $130 \cdot 24$ & $132 \cdot 3$ & $170^{\circ}$ & 28.3 & 283 & $90^{2}$ & 3.41 & $3 \cdot 40$ \\
\hline 240 & $111 \cdot 13$ & 111.24 & & 2246 & 226 & & & $2 \cdot 45$ \\
\hline 230 & 93.94 & $94 \cdot 1$ & 150 & $17 \cdot 7$ & 180 & 70 & 1.85 & 1.76 \\
\hline 220 & $78 \cdot 67$ & 78.5 & 140 & $15+8$ & 13.9 & 60 & $1 \cdot 35$ & 1.23 \\
\hline 210 & $65 \cdot 29$ & 65.0 & 190 & 1065 & 106 & 50 & 0.97 & 86 \\
\hline 200 & $59 \cdot 69$ & $53 \cdot 0$ & 120 & $8 \cdot 16$ & $8 \cdot 10$ & 40 & 0.69 & 0.56 \\
\hline 190 & $43 \cdot 76$ & $43 \cdot 2$ & 110 & 6.2 & 6.00 & 90 & 0.49 & c. 38 \\
\hline 180 & $35 \cdot 35$ & 34.73 & 100 & 4.67 & 4.50 & & & \\
\hline
\end{tabular}

$\frac{28 \cdot 3}{1 \cdot 26}=22 \cdot 46.228 .3 \times \overline{1 \cdot 26-011}=35 \cdot 35$

$28.3 \times \overline{1 \cdot 26-011} \times \overline{1 \cdot 26-0.22}=43.768 \mathrm{c}$.

$\frac{22 \cdot 46}{1 \cdot 27 !}=17 \cdot 7,8 \mathrm{c}$.

The correspondence here exhibited between the observed and calculated elasticities is remarkable ; nor does the difference ever exceed what would be produced by an error of $1^{\circ}$ in the construction or reading off of the thermometer. This may fairly be deemed the limit of accuracy in such an experiment.

Oil of turpentine is regulated by the constant ratio $1 \cdot 122$, which converts any elastic force into that $10^{\circ}$ above or below, multiplying as usual in the former, and dividing in the latter case. For petroleum the ratio is $1 \cdot 14$; it is also constant.

The following table exhibits a comparative view of theory and experiment.

Taele VI.

\begin{tabular}{|c|c|c||c|c|c|}
\hline \multicolumn{3}{|c||}{ Oil of Turpentine. } & \multicolumn{3}{c|}{ Petroleum. } \\
\hline Temp. & Calculat. & Observed. & Temp. & Calculat. & Observed. \\
\hline $310^{\circ}$ & & $33 \cdot 5$ & $320^{\circ}$ & & $31 \cdot 7$ \\
320 & $37 \cdot 7$ & $37 \cdot 06$ & 330 & $36 \cdot 2$ & $36 \cdot 4$ \\
330 & $42 \cdot 5$ & $42 \cdot 1$ & 340 & $41 \cdot 2$ & $41 \cdot 6$ \\
340 & $47 \cdot 7$ & $47 \cdot 3$ & 350 & $47 \cdot 0$ & $46 \cdot 86$ \\
350 & $53 \cdot 5$ & $53 \cdot 8$ & 360 & $53 \cdot 6$ & $53 \cdot 3$ \\
360 & $60 \cdot 4$ & $60 \cdot 8$ & 370 & $61 \cdot 1$ & $60 \cdot 7$ \\
\hline
\end{tabular}


The whole of the preceding research is closely interwoven with a question of the first importance in chemical philosophy; what are the relative portions of temperature denoted by the graduations of our thermometric scale? Mr. Dalton regards the progressive elasticities of aqueous and ethereal vapour as affording countenance, if not support, to his thermometric innovations. He affirms, that if our instrument for the measuring heat were accommodated to his doctrine, the quantity of expansion of its mercury is as the square of the temperature from its freezing point; then " the force of steam in contact with water increases accurately in geometrical progression to equal increments of temperature, provided these increments are measured by a thermometer of water or mercury, the scales of which are divided by the above-mentioned law *.;

Were this position true, it would certainly bring a powerful analogy in aid of his theoretical views. We are now furnished with data to verify, or refute it. The following tables show the correspondence between that principle and experiment. In the table of aqueous vapour, the first column presents his geometrical progression of that vapour, coordinate with his equal intervals of real temperature contained in the second. In the third, are the coresponding points of the common scale, as given by Mr. Dalton. To these points the elastic forces, as determined by experiment, are placed opposite in the fourth column.

Table second, for vapour of ether, is similarly arranged; the first three columns being Mr. Dalton's; the fourth, the faithful transcript of observation.

"The force of the vapour of sulphuric ether," says Mr. Dalton, "in contact with liquid ether, is a geometrical progression, having a less ratio than that of water." "Ether, as manufactured in the large way, appears to be a very homogeneous liquid. I have purchased it in London, Edinburgh, Glasgow, and Manchester, at different times, of precisely the same quality in respect to its vapour.$+ "$ This shows that no exception can be made to my experiments on account of a supposed difference in the quality of the ether. From the mode of conducting my experiments, there remained always a quantity of liquid ether in contact with the vapour, a circumstance essential to accuracy in this research. The results were verified by frequent repetitions, and discover, in my opinion, the consistency of truth.

$$
\text { * New System, vol. i. p. } 11 . \quad+\text { Ib. pp. 20, } 21 .
$$




\section{TABLES VII. and VIII.}

DaLton's Theory of the thermometric Scale compared with the olserved Temperatures and Tensions of Vapours.

\begin{tabular}{|c|c|c|c|c|c|c|c|}
\hline \multicolumn{4}{|c|}{ Aqueous Vapour. } & \multicolumn{4}{|c|}{ Ethereal Vapour. } \\
\hline $\begin{array}{l}\text { DALTON'S } \\
\text { geom .Pro- } \\
\text { ress ion of } \\
\text { Elasticity. }\end{array}$ & $\begin{array}{l}\text { DaLron's } \\
\text { new Scale } \\
\text { of Tem- } \\
\text { perat. }\end{array}$ & 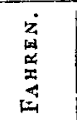 & 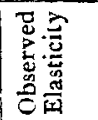 & $\begin{array}{l}\text { Dalton's } \\
\text { Progression } \\
\text { ofElasticity }\end{array}$ & $\mid \begin{array}{l}n \\
0 \\
0 \\
0\end{array}$ & 量 & 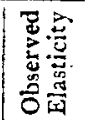 \\
\hline $22 \cdot 7$ inch. & $202^{\circ}$ & $199^{\circ}$ & 23.1 in & 6. & $32^{\circ}$ & $32^{\circ}$ & \\
\hline & 212 & 212 & & & 52 & & \\
\hline 395 & 222 & 225 & $39 \cdot 11$ & $13 \cdot 7$ & 72 & $62 \cdot 55$ & 1260 \\
\hline 52 & $2: 3$ & 238.6 & 50. & & 92 & & 18.4 \\
\hline 69 & 242 & $252 \cdot 6$ & 64.5 & 31. & 112 & 98.50 & $27 \cdot 2$ \\
\hline $9 ! 0$ & 252 & 2668 & 81.5 & & 132 & $118 \cdot 50$ & 37.7 \\
\hline $120 \cdot 0$ & 262 & 281.2 & 103.5 & & 153 & 139.9 & $56 \cdot 8$ \\
\hline 158 & 272 & $\simeq 96 \cdot 2$ & 1317 & 104 & 172 & $162 \cdot 4$ & $83 \cdot 3$ \\
\hline 208 & 282 & $311 \cdot 5$ & 164.8 & & 192 & 186.5 & 118.3 \\
\hline & & & & & 212 & & $169 \cdot 0$ \\
\hline
\end{tabular}

The numbers of the first and fourth column ought evidently to agree, if the theory be just. Their differences, on the contrary, are prodigiously great. At $272^{\circ}$ of his scale, for example, equal to $296^{\circ} \cdot 2$ of ours, the law of progression makes the elastic force of aqueous vapour amount to 158 inches: experiment gives 131.7 ; and 1. am confident, that the latter cannot be in error above an inch or two. Again at $262^{\circ}$, equivalent to $281^{\circ} \cdot 2$ Fahrenheit, his theory gives the force of the sane vapour at 120 inches; by observation it is only 103.5. Now at this part of the scale, my result is confirmed by the concurrence of those obtained by Betancourt and Robison. I consider this demonstration complete. If we compare these very elasticities of Mr. Dalton, with the table formerly given by the same philosopher *, we shall find discordances which no ingenuity can harmonize. At that time, $225^{\circ}$ of Fahr. $=222^{\circ}$ of the new scale, gave a force of vapour equal to $38 \cdot 3$; it is now $39 \cdot 5 \cdot 252^{\circ} \cdot 6 \mathrm{~F} .=242^{\circ} \mathrm{D}$. then coincided with an elasticity of $58 \cdot 6$ inches; above, it is 69 . And finally, $281^{\circ} \cdot 2 \mathrm{~F} .=262^{\circ} \mathrm{D}$. were opposite to 90 inches; they have become here 120. And yet no new experiments on the vapour of water have been adduced, to justify such immense alterations.

It may be said, indeed, that these changes arise merely from the substitution of one hypothesis for another; but the deviations from experiment are even more remarkable, since as $282^{\circ}$ new scale, correspond to $31 \mathrm{l}^{\circ} .5 \mathrm{Fahr}$, the difference amounts to 43 inches, being more than one-fourth of the total elastic force generated at that high temperature.

* Manchester Memoirs, vol. v. 
When we turn our attention to ether, we find the discrepancies, if possible, less easy to reconcile. At the temperature of $212^{\circ}$, for example, where the old and new scales meet for the last time, the force of its vapour by the geometrical progression exceeds that found from experiment, by the enormous quantity of 67 inches and a half; amounting to two-fifths of the whole elastic force evolved.

May we venture, then, to conclude, from these multiplied comparisons, that the progressions of elasticity in vapours, taught by Mr. Dalton, are geometrical fictions, intended to quadrate with his notions concerning temperature; but not consonant with the laws or phænomena of pature?

Within a moderate compass, indeed, it is not difficult to suit the ratio of elastic force and the thermometric graduation to each other; but the prosecution of the inquiry into ranges more remote, detects the fallacy of such hypothetical adaptations. My experiments on the vapours of water, alcohol and ether, seem to show, that the ratio of tension decreases in a certain progression as the temperature augments. Were the ratios $1 \cdot 23,1 \cdot 22$, $1 \cdot 21,8 z$., which are seen to apply so well to aqueous vapour for a considerable range above $212^{\circ}$, to be adopted as representing the progressive march of nature, it would lead to the absurd conclusion, that at $240^{\circ}$ above the boiling point, or $452^{\circ} \mathrm{F}$., the further influx of caloric would occasion a diminution of elasticity in the steam. The truth however is, that at the 312th degree, indications of a divergence begin to appear between the two lines of experiment and calculation, which had run for so long a space nearly parallel. The curve representing the expansive force of steam, I consider to be logarithnic, in which the ratios, as ordinates, continually diminish, without ever vanishing, or coming to an equality. The axis is an asymptote to the curve, as in the atmospherical logarithmic.

[To be continued.]

XVI. On Wheel-Carriages and their Effects upon Roads. By Mr. John FAREY Sen. Mineral Surveyor.

\section{To Mr. Tilloch.}

Sir, $\mathbf{I}_{\text {AM glad to see the important suhjects of Wheel-carriages }}$ and Roads, brought under the notice of your readers, by the communication of Mr. Benjamin Wingrove, in your last Number; wherein he recommends two important improvements; viz.to prevent or lessen the evils of dragging waggon wheels down the hills, and the constructing of curriages of an uniform breadth, so that their wheels repeatedly follow in the same tracks, and cut ruts in 